\title{
Development and Characterization of Mechanically Alloyed and Sintered (Al-7wt.\%Si)-2wt.\%VB Composites
}

\author{
Sıddıka Mertdinç ${ }^{1}$, Emre Tekoğlu ${ }^{1}$, Duygu Ağaoğulları ${ }^{1}$, Hasan Gökçe ${ }^{2}$, M. Lütfi Öveçoğlu ${ }^{1}$ \\ ${ }^{1}$ Istanbul Technical University, Chemical and Metallurgical Engineering Faculty, Metallurgical and Materials Engineering \\ Department, Particulate Materials Laboratories (PML), 34469 Maslak, Istanbul, Turkey \\ mertdinc@itu.edu.tr; tekoglue@itu.edu.tr; bozkurtdu@itu.edu.tr; ovecoglu@gmail.com \\ ${ }_{2}^{2}$ Istanbul Technical University, Prof.Dr. Adnan Tekin Materials Science and Production Technologies Applied Research \\ Center (ATARC),34469 Maslak, Istanbul, Turkey \\ gokceh@itu.edu.tr
}

\begin{abstract}
Vanadium boride (VB)particulate reinforced Al-7 wt.\% Si based metal matrix composites (MMC) were synthesized using mechanical alloying (MA) and pressureless sintering. (Al- 7 wt. \% Si)-2 wt.\% VB blends were mechanically alloyed for $4 \mathrm{~h}$ in a high energy ball mill. Particle size measurement, Brunauer-Emmett-Teller (BET) surface area analysis, scanning electron microscopy (SEM) investigation and thermal analysis were conducted to characterize the mechanically alloyed powders. As-blended and mechanically alloyed powders were compacted in anuniaxial hydraulicpress with a pressure of $450 \mathrm{MPa}$ and green compacts were sintered at $570^{\circ} \mathrm{C}$ under Ar gas flowing conditions. Microstructural and phase characterizations of the sintered samples were carried out using optical microscope (OM), SEM and X-ray diffractometer (XRD). Physical and mechanical properties of the sintered composites were investigated in terms of density measurements, microhardness measurements and wear rate. MA enhances the physical and mechanical properties of the composites. (Al-7 wt.\% Si)-2wt.\% VB MA'd for $4 \mathrm{~h}$ had relative density value of $95.55 \%$, microhardness value of $1.04 \pm 0.11 \mathrm{GPa}$ and wear rate of $1.42 \times 10^{-5} \mathrm{~mm}^{3} / \mathrm{mm}$.
\end{abstract}

Keywords: Al-Si based metal matrix composites, Vanadium boride, Mechanical alloying, Pressureless sintering

\section{Introduction}

Aluminium based MMCs have been used in many areas such as aerospace, aircraft, automotive, and other industrial applications due to their low density, high strength, high elastic modulus, high wear and corrosion resistances and good thermal stabilities [1-3].

Al-based MMCs have been usually fabricated via liquid-phase production techniques such asstir casting, squeeze casting, etc. However, it is possible to fabricate MMCs by solid-state production techniques especially powder metallurgy [4]. Mechanical alloying (MA) which is a high energy ball milling process is a novel part of the powder metallurgy. In MA, components are subjected to repeated cold welding, fracturing and rewelding due to the collisions of the balls in a highimpact vial environment and hence homogeneous distribution can be achieved [5].

Carbides, nitrides, oxides and borides ( $\mathrm{TiC}, \mathrm{SiC}, \mathrm{ZrC}, \mathrm{Si}_{3} \mathrm{~N}_{4}, \mathrm{ZrO}_{2}, \mathrm{Al}_{2} \mathrm{O}_{3}, \mathrm{TiB}_{2}, \mathrm{ZrB}_{2}$ etc.) are used as reinforcement materials for Al-based MMCs [6,9-10]. These particulate reinforcement materials improve the mechanical properties of the composite materials [3]. Amongst them, vanadium boride (VB) has high melting point, good wear and corrosion resistance, high hardness, high electrical and thermal conductivities and high chemical stability. Therefore, VB can be used as reinforcement material for Al-based MMCs to improve their hardness and wear resistance[7,8].

\section{Experimental Procedure}

In this study, the starting materials were elemental aluminium (Al) powders (Alfa Aesar ${ }^{\mathrm{TM}}, 99.5 \%$ purity, $12 \mu \mathrm{m}$ ) and silicon (Si) powders (Alfa Aesar ${ }^{\mathrm{TM}}, 99.99 \%$ purity, $<20 \mu \mathrm{m}$ ). Al and 7wt. \% Si (Al7Si) based metal matrix alloy was reinforced with 2 wt. \% commercial vanadium boride (VB) (Alfa Aesar ${ }^{\mathrm{TM}}, 99.5 \%$ purity, $\leq 44 \mu \mathrm{m}$ ) particles.

Powders were mixed with 2 wt.\% stearic acid $\left(\mathrm{CH}_{3}\left(\mathrm{CH}_{2}\right)_{16} \mathrm{COOH}\right)(\mathrm{ZAG}, 99.5 \%$ purity)which is a process control agent (PCA) to prevent excessive cold welding and agglomeration of the powders into a hardened steel vial. Powders were loaded into vial in a glove-box (Plaslabs ${ }^{\mathrm{TM}}$ ) by evacuating and filling with high purityAr gas (Linde ${ }^{\mathrm{TM}}, 99.999 \%$ purity) using 
a 7/1 ball-to-powder weight ratio. Blended powders were mechanically alloyed in a high energy ball mill (Spex ${ }^{\mathrm{TM}} 8000 \mathrm{D}$ Mixer/Mill, $1200 \mathrm{rpm}$ ) for $4 \mathrm{~h}$.

Phase analyses of the as-blended and MA'd powders were performed by using a Bruker ${ }^{\mathrm{TM}} \mathrm{D} 8$ Advanced Series X-ray diffractometer (XRD) with $\mathrm{CuK} \alpha$ radiation $\left(35 \mathrm{kV}, 40 \mathrm{~mA}, 2 \theta\right.$ range of $10-90^{\circ}$ with a scan rate of $\left.2^{\circ} / \mathrm{min}\right)$. Microstructural investigations of powders were performed using $\mathrm{JEOL}^{\mathrm{TM}}-6000$ Neoscope model scanning electron microsope (SEM). Particle size analyses (PSA) of the powders were conducted with a NanoFlex ${ }^{\mathrm{TM}}$ particle sizer. Zeta potentials of the particles were changed from $\sim \mathrm{pH}=5$ to $\mathrm{pH}=9$ with $\mathrm{Stabino}{ }^{\mathrm{TM}}$ with $\mathrm{NaOH}$ titrations to disperse the $\mathrm{Al}$ powders in water media. Also, Brunauer-Emmett-Teller(BET) surface area analysis was conducted to determine the surface area of the MA'd powders. Thermal analysis was conducted using a TA ${ }^{\mathrm{TM}}$ Instruments SDT Q600 differential scanning calorimeter (DSC) to determine the sintering temperature of the MA'd samples.

After the characterization investigations, powders were compacted using a MSETM uniaxial hydraulic press with 450 $\mathrm{MPa}$. PCA was removed from the bulk samples by heating them up to $420{ }^{\circ} \mathrm{C}$ under Ar atmosphere in a MTI ${ }^{\mathrm{TM}}$ tube furnace. After the debinding process, samples were sintered at $570{ }^{\circ} \mathrm{C}$ with a heating and cooling rate of $5^{\circ} \mathrm{C} / \mathrm{min}$ in a Linn ${ }^{\mathrm{TM}} \mathrm{HT}$ 1800 high-temperature controlled-atmosphere furnace under vacuum and Ar atmosphere.

XRDanalyses were conducted to determine the phases of the sintered samples. Microstructural investigations were performed using Nikon ${ }^{\mathrm{TM}}$ Eclipse L150 model optical microscope (OM). Densities of the samples were calculated using the Archimedes method. Hardness measurements of the composites were carried out in a Shimadzu ${ }^{\mathrm{TM}}$ Vickers microhardness tester under a load of $100 \mathrm{~g}$ for $10 \mathrm{~s}$. Sliding wear tests conducted with a Tribotech ${ }^{\mathrm{TM}}$ model tribotester using with a $100 \mathrm{Cr} 6$ steel ball ( $\phi 6 \mathrm{~mm}$ diameter) under $3 \mathrm{~N}$ loading (sliding speed: $10 \mathrm{~mm} / \mathrm{s}$, stroke length: $5 \mathrm{~mm}$, total sliding distance: 25000 $\mathrm{mm}$ ). The results in the study were repeated two times in order to eliminate the experimental and individual errors.

\section{Results and Discussion}

XRD patterns of the as-blended and $4 \mathrm{~h}$ of MA'dAl-7 wt.\% Si-2wt.\% VBpowders and their sintered samples are shown in Figure 1(a) and (b). XRD results verified the presence of the Al, Si and VB phases in the powder and bulk systems. There are no secondary phases and intermetallics between the Al, Si and VB phases, or Fe impurity worn from the milling vials/balls during the mechanical alloying, within the detection limit of diffractometer ( $\geq 2 \mathrm{wt} . \%$ of the overall sample).Crystallite sizes and lattice strains of the dominant $\mathrm{Al}$ phase in the powders were calculated by the TOPAS softwareusing the XRD patterns of the powders. Crystallite sizes decreased and lattice deformations increased with increasing MA time. Crystallite sizes of the as-blended and MA'd powders are $407.10 \mathrm{~nm}$ and $67.93 \mathrm{~nm}$, respectively. Besides, lattice strains change from $0.050 \%$ to $0.326 \%$ by the effect of MA.

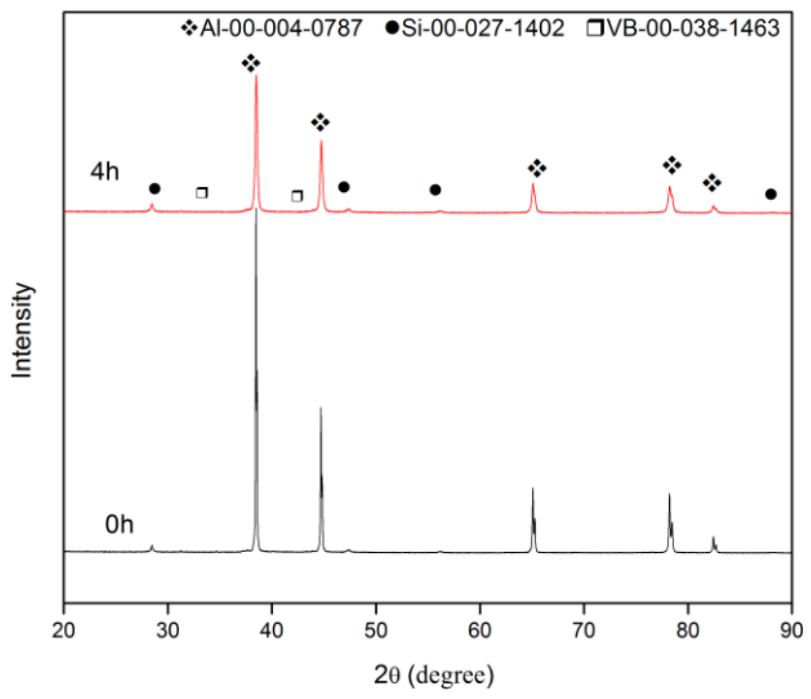

(a)

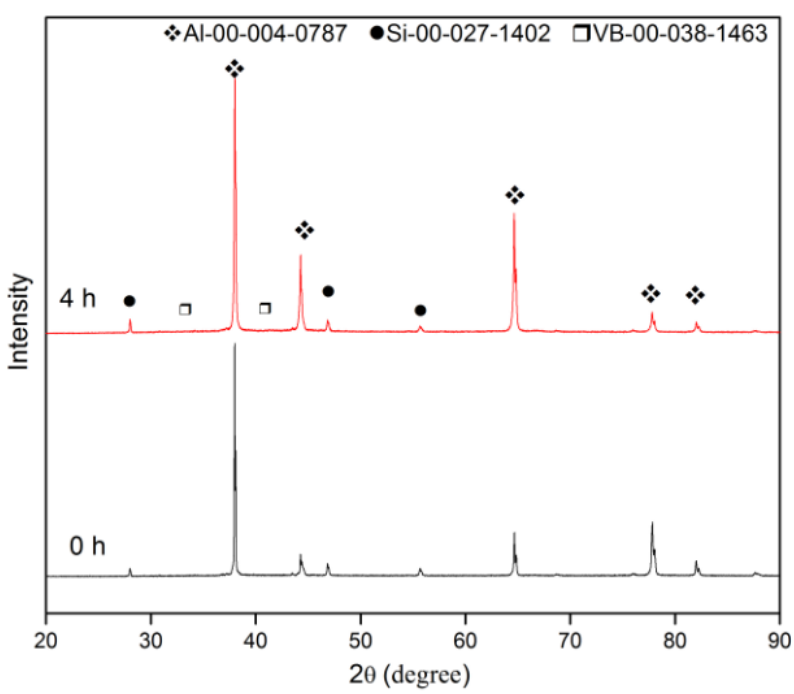

(b)

Fig. 1: XRD patterns of the as-blended and 4h ofMA'dAl-7wt.\% Si-2wt.\% VB (a) powders, and (b) their sintered samples. 
SEM images showthat $4 \mathrm{~h}$ of MA'dpowders have different morphology from the as-blended ones, as seen in Figure 2. Ductile $\mathrm{Al}$ powders transformed to flaky-shaped and equiaxed-shaped structures due to the mechanical impacts in the milling environment. Subsequently, Si and VB particles could be easily embedded into the Al matrix.

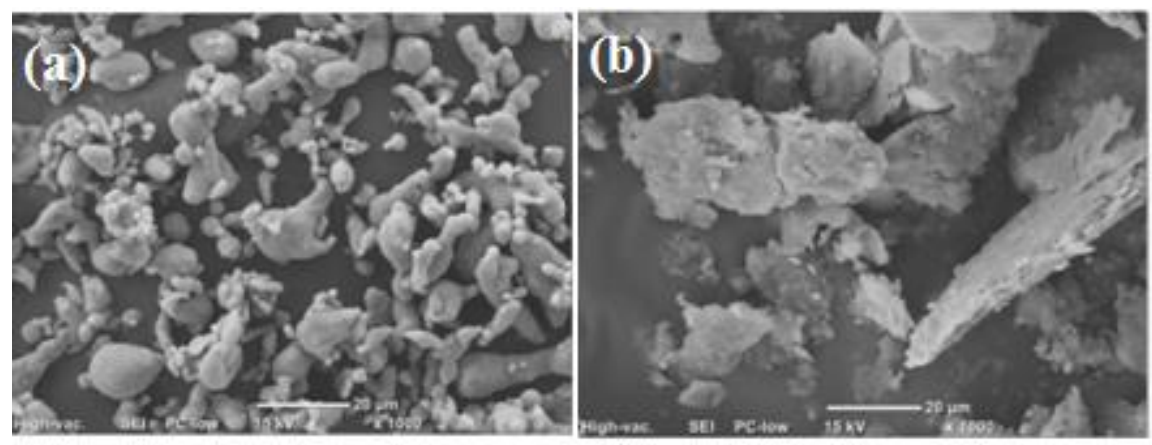

Fig. 2: SEM images of the (a) as-blended and (b) $4 \mathrm{~h}$ of MA'd Al-7wt.\% Si-2wt.\% VB powders.

Particle sizes of the powders were determined by using laser diffraction technique. Particle size of the 4h of MA'd powders decreased to $0.376 \mu \mathrm{m}$. Bimodal particle size distribution is seen in Figure 3. Results of the BET calculations show that surface area of the powders are about $6.58 \mathrm{~m}^{2} / \mathrm{g}$.

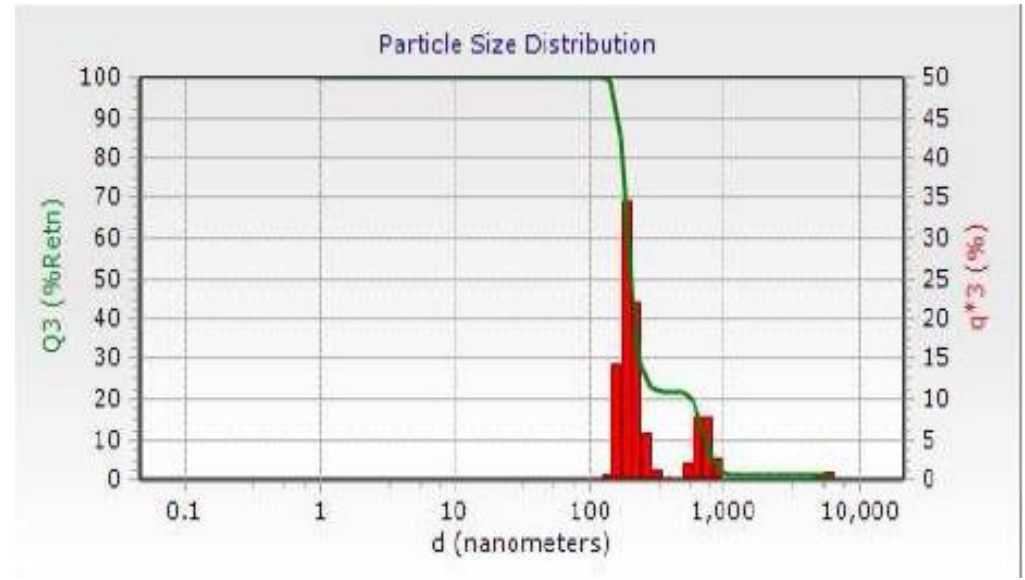

Fig. 3: Particle size distribution of the 4h of MA'dAl-7wt.\% Si-2wt.\% VBpowders.

Thermal analysis was conducted to determine the sintering temperature of the mechanically alloyed samples (Figure 4). The endothermic peak at $578.89^{\circ} \mathrm{C}$ shows that the $\mathrm{Si}$ contributedto the $\mathrm{Al}$ structure and shifted the melting temperature to nearly eutectic temperature.Therefore, $570^{\circ} \mathrm{C}$ is selected as the sintering temperature to perform solid-state sintering.

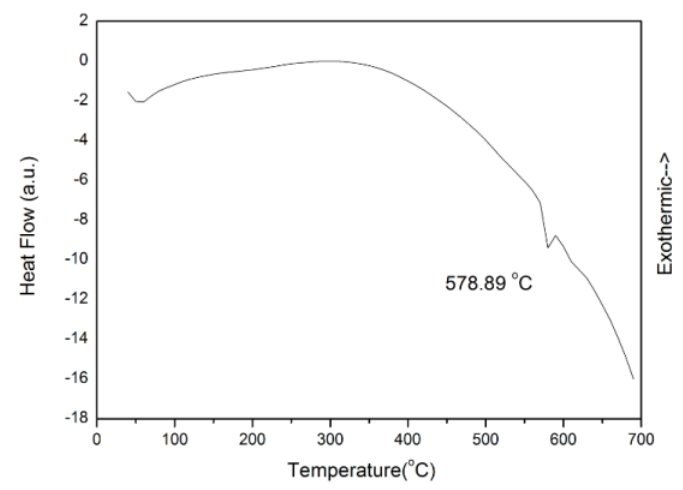

Fig. 4: DSC scan of the $4 \mathrm{~h}$ of MA'dAl-7wt.\% Si-2wt.\% VB powders. 
From the optical microscope images in Figure 5, there is not a homogeneous distribution of the particles in the microstructure of the as-blended and sintered sample due to the clustering of the particles (Figure 5(a)).During MA, Si and VB phasesincorporated into the Al matrix anda homogeneous microstructure was obtained (Figure 5(b)).
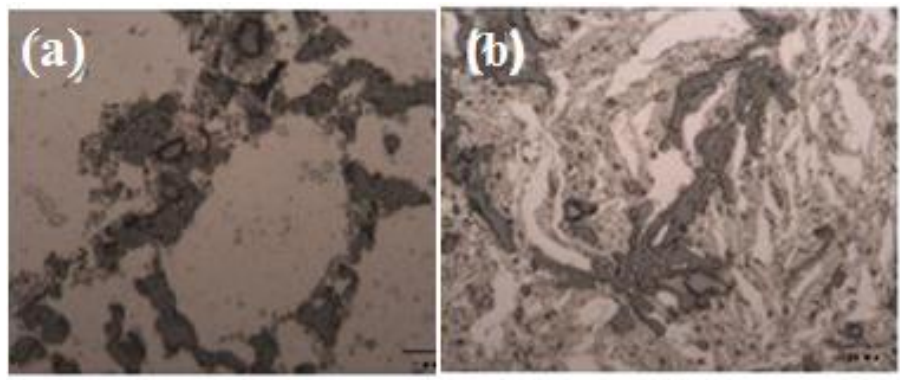

Fig. 5: OM images of the sintered Al-7wt.\% Si-2wt.\% VB composites originated from: (a) as-blended (1000x) powders and (b) 4 h ofMA'dpowders (1000x).

Relative density and microhardness results of the as-blended or MA'd and sintered samples are given at Table 1. Measured densities showed that MA'd and sintered samples reached to $95.55 \%$ of the theoretical density. Moreover, the increase in the microhardness value of the MA'd and sintered sample is nearly twice of the as-blended and sintered sample (from $0.48 \mathrm{GPa}$ to $1.04 \mathrm{GPa}$ ). MA'd and sintered Al-7wt.\% Si-2wt.\% VB composite hasthe wear rate of $1.42 \times 10^{-5} \mathrm{~mm} / \mathrm{N} . \mathrm{m}$. Also, OM and SEM images of the worn surfaces belonging to the $4 \mathrm{~h}$ of MA'd and sintered Al-7wt.\% Si-2wt.\% VBcomposite are shown in Figure 6(a) and (b), respectively.

Table 1: Density and microhardness values of the as-blended or 4h of MA'd and sintered Al-7wt.\% Si-2 wt.\% VB composites.

\begin{tabular}{|c|c|c|c|c|}
\hline \multirow{2}{*}{$\begin{array}{c}\text { MA } \\
\text { time }\end{array}$} & $\begin{array}{c}\text { Theoroticaldensity } \\
\left(\mathbf{g} / \mathbf{c m}^{\mathbf{3}}\right)\end{array}$ & $\begin{array}{c}\text { Archimedes } \\
\mathbf{d e n s i t y} \\
\left(\mathbf{g} / \mathbf{c m}^{\mathbf{3}}\right)\end{array}$ & $\begin{array}{c}\text { Relative } \\
\text { density } \\
\mathbf{( \% )}\end{array}$ & $\begin{array}{c}\text { Vickers } \\
\text { microhardness } \\
(\mathbf{G P a})\end{array}$ \\
\cline { 1 - 4 } as-blended & \multirow{2}{*}{2.69} & 2.487 & 92.25 & $0.48 \pm 0.06$ \\
\cline { 1 - 4 } 4h $\mathrm{h}$ & 2.576 & 95.55 & $1.04 \pm 0.11$ \\
\hline
\end{tabular}

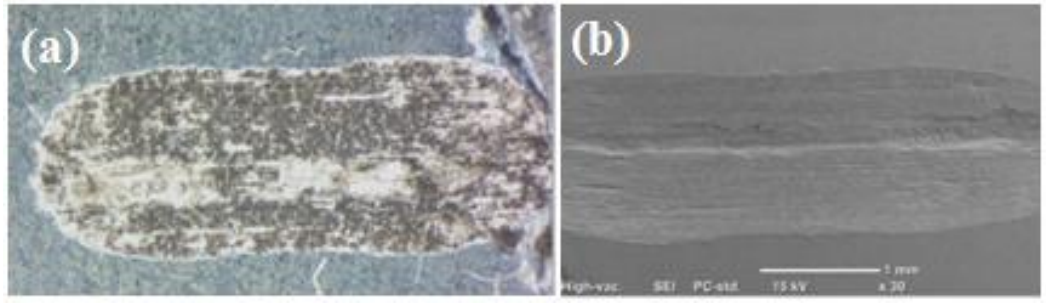

Fig. 6: (a) OM and (b) SEM (30x) images of the worn surfaces of the $4 \mathrm{~h}$ of MA'd and sintered Al-7wt.\% Si-2wt.\% VB composite.

\section{Conclusion}

Mechanical and physical properties of the VB particulate reinforcedAl-7wt.\% Si MMCs were improved with mechanicalalloying process probably due to the homogeneous distribution of the powder particles. Relative density and microhardness values of the MA'd and sintered sample reached to 95.55\% and $1.04 \mathrm{GPa}$, respectively. Also, MA'd and sintered sample had the wear rate of $1.42 \times 10^{-5} \mathrm{~mm}^{3} / \mathrm{N}$.m.

\section{Acknowledgements}

This study was supported by "The Scientific and Technological Research Council of Turkey (TÜBİTAK)" with the project number of 214M093. 


\section{References}

[1] M. Surappa, “Aluminium matrix composites: Challenges and opportunities," Sadhana, pp. 319-334, 2003.

[2] J. M. Torralba, C. E. Da Costa, and F. Velasco, "P/M aluminium matrix composites: an overview," Journal of Materials Processing Technology, vol. 133, no. 1-2, pp. 203-206, 2003.

[3] K. Kainer, "Metal Matrix Composites: Custom-made Materials for Automotive and Aerospace," Viley-VCH, 2003.

[4] Y. Nishida, "Introduction to Metal Matrix Composites Fabrication and Recycling", Springer, 2013, pp. 1-43, Japan.

[5] C. Suryanarayana, E. Ivanov, and V. V. Boldyrev, "The Science and Technology of Mechanical Alloying," Materials Science and Engineering A, vol. 304-306, pp. 151-158, 2001.

[6] Ö. Balc1, D. Ağaoğulları, H. Gökçe, İ. Duman, and M. L. Öveçoğlu, "Influence of TiB 2 particle size on the microstructure and properties of $\mathrm{Al}$ matrix composites prepared via mechanical alloying and pressureless sintering," Journal of Alloys and Compounds, vol. 586, no. 1, pp. 78-84, 2014.

[7] S. A. Hassanzadeh-Tabrizian, D. Davoodi, A. A. Beykzadehb, and S. Salahshour, "Fast mechanochemical combustion synthesis of nanostructured vanadium boride by a magnesiothermic reaction," Ceramics International, vol. 42, pp. 1812-1816, 2016.

[8] C. L. Yeh and H. J. Wang, "Combustion synthesis of vanadium borides," Journal of Alloys and Compounds, vol. 509, pp. 3257-3261, 2011.

[9] H. Cui, F. Lu, X. Tang, and S. Yao. "Reinforcement Behavior in Laser Welding of A356/TiB 2 p MMCs," Materials Transactions, vol. 53, pp. 1644-1647, 2012.

[10] R. Maiti and M. Chakraborty, "Synthesis And Characterization Of Molybdenum Aluminide Nanoparticles Reinforced Aluminium Matrix Composites," Journal of Alloys and Compounds, vol. 458, pp. 450-456, 2008. 